\title{
CILJEVI, STRUKTURA I ORGANIZACIJA DODATNIH AKTIVNOSTI IZ OBLASTI IKT U RAČUNARSKOJ GIMNAZIJI SMART
}

\author{
Marina Savić \\ Univerzitet Singidunum, \\ Beograd, Srbija
}

Odgovorno lice:

Marina Savić

e-pošta:

marina.savic.14@singimail.rs

\section{Rezime:}

Postupak donošenja nastavnih planova za profile koji se školuju u srednjim školama karakterisan je rigidnošću i sporošću koja, posebno za profile orijentisane ka IKT industriji, uzrokuje visok stepen neusklađenosti nastavnih sadržaja sa konkretnim potrebama tržišta radne snage i konkretnim zahtevima za uspešan nastavak školovanja učenika.

Za uspešno sprovođenje nastavnog procesa u savremenim uslovima, neophodan je visok nivo kompetencija nastavnog kadra, kako onog čija je uža specijalnost IKT domen tako i onog kojima su uža specijalnost druge domenske oblasti. U Računarskoj gimnaziji, osmišljavaju se i realizuju dodatne aktivnosti koje imaju za cilj da obezbede dopunu sadržaja iz redovnog nastavnog plana i programa, te da podignu nivo kompetencije nastavničkog kadra. Posebna pažnja se posvećuje osmišljavanju i realizaciji aktivnosti koje u ovaj proces uključuju učenike.

\section{Ključne reči:}

nastava, dodatne aktivnosti, sekcije, hakatoni.

\section{UVOD}

Savremena nastava podrazumeva upotrebu savremenih tehnologija uključujući upotrebu računara, interaktivnih tabli, projektora, elektronskih adresa, portala i elektronskog testiranja učenika ali se iz godine u godinu menja i sam način realizacije nastave.

Ukoliko je tip časa obrada, izbegava se da oblik rada bude frontalni osim u situacijama kada je to nužno neophodno a preporučuju se projektni rad i metode aktivnog rada (praktičan rad, radionica, debata, diskusija, igra uloga, brainstorming, demonstracije, igra...) uz odgovarajuća nastavna sredstva.

Razvojem informacionih tehnologija nastava je izložena veoma brzim i naglim promenama, pa je neophodno konstantno otkrivati nove trendove za nastavna sredstva i za materijale koji se koriste a u cilju podizanja kvaliteta realizacije nastave iako je sve teže predvideti buduće potrebe obrazovnog rada.

Kako bi sprovođenje nastave bilo što uspešnije, neophodan je visok nivo kompetencija nastavnog kadra (seminari, konferencije, stručna usavršavanja...), kao i efikasnijim nastavnim metodama. 
Samo informisani, kompetentni i motivisani ljudi, spremni za razvoj, mogu biti otvoreni prema društvenim promenama. [1]

U tradicionalnoj nastavi učenici nisu dovoljno angažovani, pa se to negativno odražava na njihov dalji razvoj.

Kako bi se umanjile negativne posledice za razvoj učenika iznadprosečnih sposobnosti i postignuća u jednoj ili više oblasti nauke i tehnike, organizuju se dodatne aktivnosti u okviru nastave i vannastavnih oblika vaspitno-obrazovnog rada što znači da dodatna nastava služi kao korektiv frontalnog oblika nastave. [2]

\section{NASTAVNI PROCES, KONAČNI CILJEVI I DIDAKTIČKE SMERNICE}

Nastavnik treba da teži da prilagodi nastavu individualnim sposobnostima, zahtevima i potrebama učenika:

- Razlikovanje po individualnim mogućnostima, zahtevima i potrebama učenik. unutar njihove grupe

- Usvajanje gradiva pomoću primera,

- Obezbeđivanje kapaciteta za samostalno učenje i samostalno korišćenje znanja,

- Povezivanje teorijskog konceptualnog učenja i učenja kroz konkretne primere i eksperimentisanje. [3]

Didaktički sistemi savremene nastave su:

- heuristička,

- programirana,

- problemska,

- egzemplarna i

- mentorska nastava.

Upravo iz ovih razloga, za učenike koji pokazuju veću zainteresovanost ili talenat za računarsku grupu predmeta, organizuju se dodatne aktivnosti, na kojima se dublje obrađuju odgovarajuće nastavne teme i zadaci takmičarskog nivoa.

Termini su utvrđeni rasporedom časova, s tim što je učenicima omogućeno da dodatna uputstva dobiju i putem internog portala, mail-a ili telefonom. Sekcije su podeljene u nekoliko oblasti iako je to prvobitno bila jedna Računarska sekcija.

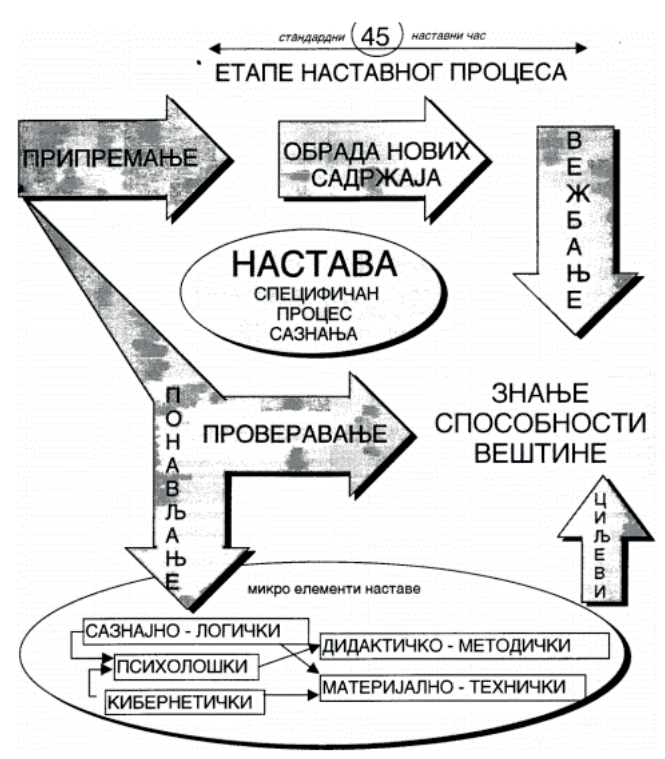

Slika 1. Etape nastavnog procesa [4]

Kako je primećeno da postoje učenici koji pokazuju veća interesovanja u oblasti programiranja ali i u oblasti grafičkog dizajna i sistem administracije, Računarska sekcija podelila se na sledeće:

- Programerska sekcija,

- Grafička sekcija,

- Hardverska sekcija,

- Hakaton sekcija.

Iako su uvedene i druge sekcije koje nisu iz oblasti IKT, u ovom radu biće opisan način realizacije sekcija koje su u direktnoj vezi sa računarskom grupom predmeta.

Dugogodišnjom analizom postojećih sistema ocenjivana i učenja, praćenjem pozitivnih primera u svetu, kao i zakonskim okvirima koje smo u obavezi da poštujemo, kreirali smo naš sistem SMART LEARNING SYSTEM - SLS primena metodologije logičkog zaključivanja kroz informatičku vizualizaciju i online reprodukciju znanja.

Osnovni ciljevi koje želimo da postignemo su:

- Objektivan sistem vrednovanja stečenog znanja,

- Stvaranje radnih navika i odgovornosti prema obavezama,

- Podsticanje na aktivan pristup nastavi,

- Sistem koji bi omogućio da se naši đaci lako uklope u svetske tokove obrazovanja,

- Primena savremenih tehnologija u službi bržeg i lakšeg trajnog usvajanja znanja. 
Učenici se motivišu da samostalno uz primenu savremenih tehnologija istražuju, pripremaju prezentaciono odgovaranje, uz primenu konstantnih provera znanja koje su ujedno i ponavljanje gradiva.

$\mathrm{Na}$ ovaj način se kod učenika utvrđuje veza rada i rezultata i pospešuju radne navike, čime se utiče na stvaranje kvalitetnije i stabilnije ličnosti, a znanje učenika je eksplicitno potvrđeno. [5]

Kao jedan od primera dobre prakse je i gostovanje vlasnika IT firmi, koji redovno drže stručne seminare u dogovoru sa profesorom koji vodi sekciju. Tom prilikom prilikom naši učenici slušaju o samom dizajniranju aplikacije, povezivanju sa bazom, REST servisima, softverskoj arhitekturi, primerima iz prakse, izazovima i problemima sa kojima se suočavaju velike kompanije, a samim tim i softver arhitekte, programeri i dizajneri. Vršnjačka edukacija je takođe prisutna na svakoj sekciji.

Interesantna stvar je da sekciju ne vode isključivo nastavnici koji predaju određeni predmet i određenoj godini. Sekciju vode profesori za koje smo doneli odluku da imaju dovoljno energije, volje, želju ali i znanje da takvu sekciju vode kvalitetno i uspešno sa grupom učenika koji su iz prve, druge, treće i četvrte godine.

\section{PROGRAMERSKA SEKCIJA}

Ovu sekciju vodi profesor računarske grupe predmeta, koji ne predaje programske jezike niti modele i baze podataka, nego predaje operativne sisteme i računarske mreže kao i računarske sisteme. Iako se po nastavnom planu i programu u školi radi C\# programski jezik, na programerskoj sekciji se koriste i PHP, Java, Python ali i HTML, CSS, JavaScript, jQuery, Ajax, Bootstrap i slično.

Zatim baze podataka poput MySql, Đango, frejmvorci Laravel, Flask, od razvojnih okruženja koriste se Visual Studio, NetBeans, Intellij IDEA kao i sistemi za upravljanje sadržajem poput WordPress-a, Joomla!-e, Drupal-a, ali i Magento-a i WooCommerce-a, koji su namenjeni za upravljanje elektronskim prodavnicama.

Na ovaj način učenici proširuju svoja znanja iz oblasti programiranja koja nisu predviđena nastavnim planom i programom.

$\mathrm{Na}$ ovoj sekciji se takođe, deca upoznaju sa realnom problematikom koju analiziraju i rešavaju uz pomoć mentora i u kontrolisanom okruženju.

U praksi se ovaj način rada pokazao kao izuzetno motivišući, jer učenici odlično reaguju na takav pristup i potpuno su skoncentrisani dok im se objašnjava na realnom primeru. To je vreme kada su i gostujuća predavanja raznih programera, dizajnera i QA testera.
Podstiče se i preduzetnišvo, te je tako i oformljeno sedam timova koji su osposobljeni za izradu web prezentacija ali i izradu web aplikacija koristeći razne tehnike i tehnologije već u drugom razredu gimnazije.

\section{GRAFIČKA SEKCIJA}

Na ovoj sekciji učenici imaju priliku da primene svoje znanje iz programiranja, baza podataka ali i da prošire svoja znanja iz ove oblasti, kao i da razviju sposobnost za timski rad i osobine koje se stiču iskustvom i obrazovanjem.

Učenici koji se istaknu na programerskoj sekciji, prelaze na Hakaton sekciju, gde se sa njima radi intenzivnije, na takmičarskom nivou.

Ova sekcija je zamišljenja kao korelacija između predmeta programiranja i umetnosti, te je s toga vode kombinovano profesor programiranja i profesor umetnosti. Ovo je važno, kako zbog web dizajna, tako i zbog dizajna likova u igricama, odnosno animacija i ilustracija koje su svakako jedna od potreba na tržištu rada. $\mathrm{Na}$ ovoj sekciji koriste se i grafičke table.

$\mathrm{Na}$ početku, učenici se upoznaju sa alatima kao što su Gimp i Krita koji su besplatni odnosno otvorenog koda, a koriste se prilikom crtanja.

Narednih časova, planirano je objašnjenje osnova alata Gimp koji se koriste pretežno za obradu fotografija i Krita, u kojem se crta. Sa profesorom umetnosti se planira dogovor oko teme a nakon toga se grafički rad realizuje upotrebom navedenih alata. Savladane su tehnike izrade i obrade digitalnih fotografija.

Kroz ovu sekciju učenici imaju priliku da budu kreativni i maštoviti, da primene svoje znanje iz programiranja i da razviju sposobnost za timski rad.

\section{HARDVERSKA SEKCIJA}

Hardversku sekciju vodi profesor koji predaje Primenu računara. Primena računara je predmet koji učenici imaju sve četiri godine.

$\mathrm{Na}$ ovoj sekciji, aktivnosti su usmerene na to da se učenici osposobe za samostalno sklapanje konfiguracija, čišćenje računara i umrežavanje računare i perifernih uređaja.

Praktičan rad je pravljenje jezgra jednog jednostavnog operativnog sistema (korišćenjem već naučenog proceduralnog jezika) i na njemu demonstracija najvažnijih funkcija operativnih sistema. 
Na ovoj sekciji, učenicima je objašnjeno na šta treba da obrate pažnju usled kupovine novog računara, koje vrste računara postoje, koje su osnovne komponente računara i njihova funkcija. Zatim, naučili su koja je razlika između HDD-a i SSD-a, šta je matična ploča, šta je napojna jedinica odnosno napajanje a nakon čega su sami a pod nadzorom mentora, menjali napajanje na računaru.

Nakon toga, instalacija različitih operativnih sistema i upoznavanje sa okruženjem je za učenike bilo jednako interesantno i korisno. Instalacija i reinstalacija operativnih sistema je jedna od aktivnosti koja se dešava upravo u okviru ove sekcije kao i spašavanje podataka sa HDD-a ili SSD-a.

Na ovoj sekciji se učenicima objašnjava i to da postoje monitori za više namena, i koji sve tipovi ekrana postoje. Zatim veličine ekrana, šta je rezolucija, koji su tipični nivoi osvetljenja i kontrast. Šta je učestalost osvežavanja, koje je vreme odziva, šta je ugao vidljivosti i koje su preporučene rezolucije ekrana.

Zatim se prelazi na kablove odnosno vezu računarmonitor, šta je HDMI, VGA, DVI, Display Port i USB. Nakon toga radi se zadatak kako dobiti najbolji prikaz na monitoru.

\section{HAKATON SEKCIJA}

Ovu sekciju vodi profesor računarske grupe predmeta koji vodi i programersku sekciju. Na ovoj sekciji se rade zadaci i projekti na takmičarskom nivou. Učenici dobijaju zadatke koje, za unapred određeno vreme, moraju da reše i predaju. Na ovaj način spremaju se za rad pod pritiskom.

Uče se kako da formiraju timove, kako da biraju članove tima, ko mora da bude tim lider u tom timu i zašto je on potreban. Svi članovi sekcije rešavaju zadatke i iz bezbednosti računarskih sistema. Kako da zabrane pristup neovlašćenim licima, instaliraju bezbednosne zakrpe, naprave rezervnu kopiju podataka, kao i sliku celog sistema. Za taj deo koriste Acronis True Image, preko koga rade i instalaciju operativnih sistema.

$\mathrm{Na}$ ovoj sekciji, učenici se upoznaju i sa mrežnim uređajima poput ruter-a, svič-a, hab-a. Kako bi savladali podešavanja rutera, bar u onoj meri koliko je za njihov uzrast dovoljno, imali su jedan ruter na kome su morali da postave ili promene lozinku, podešavanja naziva bežične mreže i slična podešavanja koja su im data u pdf formatu, zajedno sa priloženim fotografijama kako bi se učenici lakše snašli ali i kako bi oni koji su bili sprečeni da dođu taj dan na sekciju, sami kod kuće mogli uspešno da završe zadatak.
Kako bi se bolje upoznali sa računarskim mrežama, koristimo Cisco Network Academy platformu, kao i različite operativne sisteme među kojima je i Kali Linux za testiranje bezbednosti.

Sledeći alat koji se koristi je WireShark, koji služi za analizu saobraćaja.

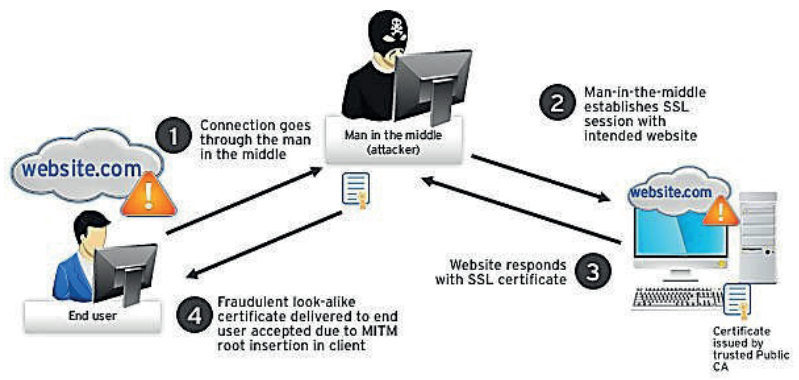

Slika 2. The Man-in-the-Middle (MITM) Attack [5]

Učenici obrađuju i tehnike socijalnog inženjeringa, kako bi znali da zaštite i sebe i druge u slučaju takvih napada.

Socijalni inženjering je čin prevare, da se otkriju informacije ili preduzme neka akcija i to obično kroz tehnologiju. Ideja socijalnog inženjeringa je da iskoristi prirodne tendencije i emocionalne reakcije potencijalne žrtve.

\section{PRAKTIČNA ISKUSTVA I SARADNJA SA DRUGIM KOMPANIJAMA}

Kao sastavni deo projektnih timova škole, učenici gimnazije će praktično naučiti kako da projektuju i razvijaju nova rešenja i aplikacije na više različitih platformi.

Učenici tokom školovanja imaju priliku da se i praktično oprobaju u oblasti Informacionih tehnologija za šta se i pripremaju u budućnosti. Imaju priliku da obilaze IT i druge kompanije gde mogu da se upoznaju sa delokrugom rada informatičara kako administratora tako i programera, ali i inženjera informacionih tehnologija.

Kroz stručnu praksu u saradnji sa specijalizovanim IT kompanijama, kroz rad na projektima učenici će imati mogućnost da primene stečeno znanje i da steknu veštine potrebne za dalje zapošljavanje nakon završetka srednje škole. [6] 


\section{SERTIFIKACIJA}

Pored samih veština i znanja, đaci se od samog početka spremaju da grade svoju profesionalnu karijeru. U prilici su da steknu tri Microsoft Technology Associate i ECDL međunarodno priznate sertifikate:

Zvanična Microsoft sertifikacija: Microsoft Technology Associate (MTA):

- MTA Infrastructure

- MTA Database

- MTA Development

Zvanična ECDL sertifikacija: European Computer Driving Licence:

- Osnove informacionih tehnologija i korišćenje računara,

- Obrada teksta, tabelarne kalkulacije i baze podataka,

- Prezentacije, informacije i komunikacije. [6]

\section{ZAHVALNOST}

Zahvaljujem se koleginici, dipl. psihologu Ivani Ursić, na nesebičnoj pomoći tokom izrade ovog rada.

\section{LITERATURA}

[1] D. Mandić, M. Vilotijević, „Projektna nastava“, u Upravljanje razvojnim promenama u vaspitno-obrazovnim ustanovama Učiteljski fakultet Beograd, pp. 134-138, 2017. [elektronski dokument]. Datum preuzimanja: 28.03. 2019. Dostupno na: www.uf.bg. ac.rs/wp-content/uploads/2017/12/PROJEKTNANASTAVA.pdf.

[2] Lj.Nešić, S. Nikolić, FIZIKA 6 Priručnik za nastavnike fizike u šestom razredu osnovne škole, Izdavačka kuća KLETT doo, Beograd, Srbija, 2015. [elektronski dokument], Datum preuzimanja: 28.03.2019. Dostupno na: http://www.klett.rs/sites/ default/files/knowledge/6_fizika_prirucnik_low. pdf.

[3] M. Auchmann, L. Bauer, A. Doppelbauer, E. Holzl, S. Winkler, „Projektna nastava prijedlozi za primjenu“, K-education Projektni ured Sarajevo, Sarajevo, Bosna i Hercegovina, 2002. [elektronski dokument]. Datum preuzimanja: 28.03. 2019. Dostupno na: http://www.nastavnickovodstvo. net/index.php/literatura/category/12-inovacije-unastavi?download=110:projektna-nastava-prijedlozi-za-primjenu.

[4] J. Đorđević, Savremena nastava, organizacija i oblici. Naučna Knjiga, Beograd, 1981.

[5] Y. Perwej, N. Akhtar, F. Parwej, "A Technological perspective of blockchain security", International Journal of Recent Scientific Research, vol. 9, no. 11(A), pp. 29472-29493, Nov., 2018. doi: http:// dx.doi.org/10.24327/ijrsr.2018.0911.2869. [elektronski dokument]. Dostupno na: https://www. researchgate.net/publication/329337003_A_Technological_Perspective_of_Blockchain_Security.

[6] „Smartsistem učenjaiocenjivanja“,http://www.smart. edu.rs, http://www.smart.edu.rs/smart-learning-and -grade-system-smart-sistem-ucenja-i-ocenjivanja/ (pristup: Mart, 29, 2019). 